\title{
ZECK, Mario, Das Schwarze Korps. Geschichte und Gestalt des Organs der Reichsführung SS
}

\section{Nicolas Le Moigne}

\section{OpenEdition}

\section{Journals}

Édition électronique

URL : http://journals.openedition.org/ifha/908

DOI : 10.4000/ifha.908

ISSN : 2198-8943

Éditeur

IFRA - Institut franco-allemand (sciences historiques et sociales)

Référence électronique

Nicolas Le Moigne, «ZECK, Mario, Das Schwarze Korps. Geschichte und Gestalt des Organs der Reichsführung SS », Revue de l'IFHA [En ligne], Date de recension, mis en ligne le 01 janvier 2005, consulté le 22 septembre 2020. URL : http://journals.openedition.org/ifha/908 ; DOI : https://doi.org/ 10.4000/ifha.908

Ce document a été généré automatiquement le 22 septembre 2020.

(C)IFHA 


\title{
ZECK, Mario, Das Schwarze Korps. Geschichte und Gestalt des Organs der Reichsführung SS
}

\author{
Nicolas Le Moigne
}

1 Alors que l'importance de l'endoctrinement est un lieu commun de l'étude des totalitarismes depuis Hannah Arendt, les monographies sur la presse nazie sont paradoxalement rares, tant on a mis l'accent sur les médias alors nouveaux comme le cinéma ou la radio. M.Z. se penche ici sur l'un des principaux organes du régime, à savoir Das Schwarze Korps, la revue de la SS, qui paraît de 1935 à 1945, et atteint un tirage de 500000 exemplaires dès 1937. Le point fort de l'ouvrage est son ouverture disciplinaire, qui fait justice à la polyvalence de l'objet, à la croisée de l'histoire des structures politiques du régime nazi, de l'histoire des médias de masse et de l'analyse des mécanismes de la propagande. Le plan s'articule autour d'ensembles simples, séparés de manière un peu artificielle mais efficace, et commode pour le lecteur : les hommes, le rapport $\mathrm{au}(\mathrm{x})$ pouvoir(s), les idées, la langue, l'image. M.Z. commence par l'évocation du rédacteur en chef Gunter D'Alquen, omniprésent dans la définition de la ligne éditoriale et dans le choix des collaborateurs, complétée par des notices biographiques sur ceux-ci. Décrit comme un "non-conformiste " à l'intersection du fanatisme et du pragmatisme, D'Alquen affirme l'indépendance de sa revue, ce qui vaut paradoxalement à Das Schwarze Korps de devenir, le cas échéant, une tribune de la critique envers les décisions prises. Si Hitler n'est jamais mis en cause personnellement, les relations avec Göring, Goebbels et le SD sont difficiles, et D'Alquen ne craint pas d'évoquer régulièrement le "mécontentement populaire " - M.Z. n'hésite pas à considérer finalement la revue comme une sorte de "bureau national des plaintes " (Reichsbeschwerdenstelle). L'essentiel est pour la rédaction de pouvoir compter sur le soutien d'Himmler, auprès duquel elle semble jouir de la "liberté du fou du roi » (Narrenfreiheit). En l'occurrence, le bouffon est aussi en charge du pilori, puisque l'analyse thématique fait de Das Schwarze Korps le support de différentes «figures de l'ennemi ». Les juifs, les bolchévistes, les déviants bien sûr, mais également les Églises, surtout la catholique, ainsi que la bureaucratie et les juristes, qui pervertissent selon 
D’Alquen la dynamique radicalement novatrice du régime - ce dernier point est le plus intéressant de ce chapitre assez " attendu ", avec un paragraphe surprenant sur le sort impitoyable fait à Carl Schmitt. L'auteur insiste par ailleurs sur la vision « productiviste " de la femme et de la famille que véhicule la revue, et qui la place au pôle le moins traditionaliste du régime. Dans l'avant-dernière partie, M.Z. emboitte le pas de Viktor Klemperer, et tente de reconstituer la « grammaire » de la langue nazie telle qu'elle est parlée dans Das Schwarze Korps. Il dépeint une stylistique - celle du slogan, de la phrase lapidaire et du néologisme - et des stratégies - tourner en ridicule, simplifier, ressasser, polariser entre l'ami et l'ennemi - qui concourent à une rhétorique - celle de la persuasion étouffante. Enfin, l'analyse du support matériel, de la mise en page, de l'agencement des polices d'écriture, donne à l'ouvrage une dimension autant médiologique qu'historique, et met en perspective les analyses de contenu de manière assez heureuse - même si l'on regrette, au fil des 40 pages qui y sont consacrées, de ne pas trouver la moindre illustration à l'appui du texte.

Nicolas LE MOIGNE (MHFA) 